Article

\title{
Removal Process of Structural Oxygen from Tetrahedrons in Muscovite during Acid Leaching of Vanadium-Bearing Shale
}

\author{
Qiushi Zheng ${ }^{1,2,3(\mathbb{D})}$, Yimin Zhang ${ }^{1,2,3,4, *}$, Tao Liu ${ }^{1,2,3}$, Jing Huang ${ }^{1,2,3}$ and Nannan Xue ${ }^{1,2}$ \\ 1 Hubei Collaborative Innovation Center for High Efficient Utilization of Vanadium Resources, \\ Wuhan 430081, China; zhengqiushi93@outlook.com (Q.Z.); tkliutao@126.com (T.L.); \\ crystal208@126.com (J.H.); cbdis@aliyun.com (N.X.) \\ 2 Hubei Provincial Engineering Technology Research Center of High Efficient Cleaning Utilization for Shale \\ Vanadium Resource, Wuhan 430081, China \\ 3 School of Resource and Environmental Engineering, Wuhan University of Science and Technology, \\ Wuhan 430081, China \\ 4 College of Resources and Environmental Engineering, Wuhan University of Technology, \\ Wuhan 430070, China \\ * Correspondence: zym126135@126.com; Tel.: +86-027-6886-2057
}

Received: 21 April 2018; Accepted: 9 May 2018; Published: 11 May 2018

\begin{abstract}
Process mineralogy shows that most vanadium in mica-type black shale exists in the octahedral sites of muscovite. The extraction of vanadium mainly occurs in the acid leaching process with participation of $\mathrm{H}$ ions. In this work, we firstly analyzed the dissolution rules of elements in acid leaching of muscovite, then adopted the density functional theory (DFT) calculation to accurately visualize the primary process of the surface corrosion of muscovite by $\mathrm{H}$ ions. The experimental results show that $\mathrm{K}$ releases the fastest and the release of $\mathrm{Al}$ is consistent with $\mathrm{K}$. The simulation results find that the $\mathrm{H}$ preferentially shifts to the unsaturated structured $\mathrm{O}$ of the tetrahedron to form a strong 001 surface hydroxyl after replacing $\mathrm{K}$, as well as relaxing the near $\mathrm{Al}(\mathrm{Si})-\mathrm{O}$ bonds for the further removal of structural oxygen. Then, the 001 surface hydroxyls more likely participate in the dehydroxylation reaction through the reverse-path mechanism to remove the structural oxygen and break the hexagonal rings of the tetrahedral sheets. Remarkably, the formation and removal of structural water are overall endoergic, meaning that the disintegration of muscovite requires a sustained supply of heat. Further, the octahedral sheets where vanadium exists can be exposed to the acid environment for overall destruction. This detailed atomic migration process in acid leaching of black shale is visualized, which not only illuminates the reaction mechanism of $\mathrm{H}$ ions with the muscovite, but also provides guidance for vanadium extraction from black shale and a new concept for the destruction of other minerals.
\end{abstract}

Keywords: vanadium; muscovite; black shale; hydrogen; acid leaching; DFT

\section{Introduction}

Vanadium (V), due to its polyvalence, has been applied in various fields such as catalysis, photochemistry, material science, and medicine [1-3], and the toxicology of some vanadium species has also attracted extensive attention [4]. In China, vanadium extraction from black shales, a unique and significant vanadium resource, has developed into a systematic and diversified process $[5,6]$. Compared with water and alkaline leaching, the acid leaching process not only obtains good vanadium extraction efficiency without vast roasting additive requirements, but can also handle more complex or primary ore [7-9]. Otherwise, the acids with different kinds of anions often have different promotion 
effects during the leaching process [10,11]. Vanadium liberation essentially depends on the acid attack. Based on process mineralogy, the major minerals of mica-type shale include quartz $\left(\mathrm{SiO}_{2}\right)$, feldspar $\left(\mathrm{KAlSi}_{3} \mathrm{O}_{8}\right)$, muscovite $\left(\mathrm{KAl}_{2}\left(\mathrm{Si}_{3} \mathrm{Al}\right) \mathrm{O}_{10}(\mathrm{OH})_{2}\right)$, and a little calcite $\left(\mathrm{CaCO}_{3}\right)$ and pyrite $\left(\mathrm{FeS}_{2}\right)$ [12]. Actually, muscovite (phyllosilicate) is less thermally stable than quartz and feldspar (tectosilicate). Most V in mica-type black shale substitutes trivalent aluminium (Al) in the octahedrons as the isomorphism in muscovite [13]. It means the liberation of $\mathrm{V}$ is congruent with the dissolution of $\mathrm{Al}$. In the actual production process, the $\mathrm{V}$ can be effectively extracted by the preferential destruction of muscovite with suitable acid concentration and dosage. However, the mechanism of muscovite disintegration during acid leaching is still unclear and the atomic migration process also cannot be described in detail. Recent studies distinguish the structure destruction through the reduction or disappearance of the subject mineral using a macroscopic test. Crundwell has clearly outlined that the dissolution of minerals needs the participation of hydrogen ions and anions, and provided a theoretical framework for the mechanism of aluminosilicates dissolution in acidic solutions by the kinetics of dissolution [14,15]. It is worth clarifying the structural disintegration process of muscovite in acid leaching at the atomic level. In this paper, the disruptive behavior of $\mathrm{H}$ ions on the muscovite surface during the acid leaching process was intensively investigated. Furthermore, the reaction kinetics were hierarchically revealed based on the energy change.

The process mineralogy of mica-type black shale shows the intimate association between V-bearing muscovite and other aluminosilicates. Thus, the finely grained and poorly impregnated V-bearing muscovite is difficult to separate completely by other phases. In this study, we used pure muscovite to simulate the dissolving characteristic of V-bearing muscovite. The muscovite lattice is a 2:1 layer structure, composed of two tetrahedral sheets and one sandwiched octahedral sheet. The $\mathrm{Si}-\mathrm{O}$ tetrahedrons are connected with each other by the triangular basal oxygen to form coplanar hexagonal siloxane cavities with infinite extension in the tetrahedral sheet. The bottom faces of the Al-O octahedrons are supplemented by two hydroxyl groups at the center of the hexagonal siloxane cavities. In the tetrahedral sheet of muscovite, the quarter substitution of $\mathrm{Si}^{4+}{\text { by } \mathrm{Al}^{3+}}^{3+}$ gives the layer a net negative charge. Then, the compensated $\mathrm{K}^{+}$is filled in the layers and forms electrostatic and van der Waals interactions. This weak force between the two layers can be easily broken and the 001 surface is exposed during the leaching process. However, tetrahedral sheets of the 001 surface are thermodynamically stable to protect the octahedrons from dissolving. In order to liberate $\mathrm{Al} / \mathrm{V}$ from the octahedrons, the stable tetrahedral sheets must be primarily destroyed by acid. In tetrahedral sheets, the oxygen framework plays an important role for its thermodynamic stability. Herein, the intense destruction of $\mathrm{H}$ ions is reflected by the release of oxygen atoms. Consequently, a detailed characterization of muscovite disintegration is primarily necessary to explain how the oxygen framework of tetrahedral sheets is removed. Due to the inherent high degree of heterogeneity in octahedrons and interlayer and poor crystallizing of natural phyllosilicate, the disintegration process does not occur uniformly using a traditional method. Furthermore, the changes of the siloxane cavities are difficult to be experimentally characterized.

Nowadays, quantum chemical simulation methods have advanced considerably with respect to experimental techniques, especially for the prediction of the crystallographic properties of these minerals [16-18]. In this paper, we firstly studied the dissolution rate of each element in the muscovite to determine the general dissolution rule by leaching experiments, and further investigated the behaviors of $\mathrm{H}$ ions on muscovite 001 surfaces by means of first-principles density functional theory (DFT) calculations to characterize the structural transformations and elucidate the intrinsic properties of the muscovite disintegration process. 


\section{Materials and Methods}

\subsection{Experimental Materials}

The natural muscovite sample used in this study was obtained from Hebei Province, China. The particle size is less than $74 \mu \mathrm{m}$, consistent with the granularity of muscovite in black shale. The XRD pattern (Figure 1) indicates that the main mineral was muscovite 2M1 without any other impurities. It coincides with the configuration of muscovite in black shale. The chemical composition of muscovite is listed in Table 1.

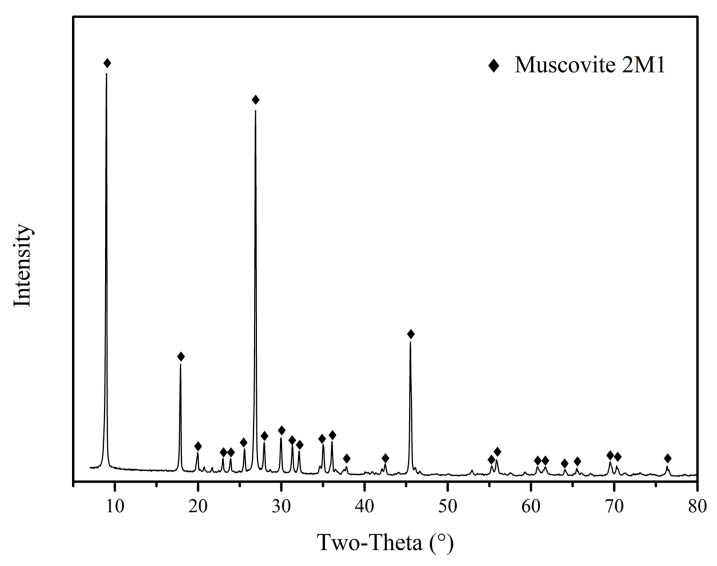

Figure 1. XRD pattern of the studied muscovite.

Table 1. Main chemical composition of the muscovite (wt \%).

\begin{tabular}{ccccccc}
\hline $\mathbf{K}$ & $\mathbf{N a}$ & $\mathbf{A l}$ & $\mathbf{M g}$ & $\mathbf{S i}$ & $\mathbf{F e}$ & $\mathbf{T i}$ \\
\hline 7.50 & 0.39 & 17.22 & 0.18 & 22.00 & 3.15 & 0.64 \\
\hline
\end{tabular}

\subsection{Muscovite Leaching}

The muscovite leaching tests were carried out in the heat collection type constant temperature magnetic heating stirrer (DF-101S) under a temperature of $90{ }^{\circ} \mathrm{C}, \mathrm{H}_{2} \mathrm{SO}_{4}$ concentration of $20 \mathrm{vol} \%$, and liquid-solid ratio of $10 \mathrm{~mL} / \mathrm{g}$. After that, the mixture was filtered by a vacuum suction filter device (SHB-III) and washed with water, then the leachate and the residue were finally collected. The chemical reagents used in this study were all of analytical grade, purchased from Sinopharm Chemical Reagent Co., Ltd., Shanghai, China. Ultrapure Milli-Q water was utilized throughout.

The leaching efficiency is calculated by $\eta$.

$$
\eta=\frac{c \cdot L}{\theta \cdot M} \times 100 \%
$$

where $\theta$ is the vanadium grade in vanadium-bearing shale, $c$ is the vanadium concentration in leachate, $L$ is the leachate volume, and $M$ is the feeding mass of ground vanadium-bearing shale.

The correlation of elements' dissolution is defined by $\gamma$.

$$
\gamma=\lg \left(\frac{R_{\mathrm{aq}}}{R_{\mathrm{solid}}}\right)
$$

where $R_{\mathrm{aq}}, R_{\text {solid }}$ are the molar concentration ratio of two elements in acid solutions and in bulk solid, respectively. $\gamma \neq 0$ means the incongruent dissolution which leads to non-stoichiometric leaching of muscovite.

\subsection{Structure Calculations}

All periodic DFT calculations were performed with the Vienna ab initio simulation package (VASP) [19,20]. The generalized gradient approximation (GGA) with the function of PBE-version [21,22] 
was envisaged to deal with the exchange-correlation energy, and the electron-ion interactions were described by the projector augmented wave (PAW) method [23,24]. A tested kinetic energy cutoff value of $800 \mathrm{eV}$ was utilized to expand the plane-wave function. Brillouin zones were sampled with $8 \times 4 \times 2 \Gamma$-point centered $k$-points mesh in the calculations of unit cell of muscovite, and $4 \times 4 \times 1$ for muscovite (001) surface calculations.

The initial crystal structure of muscovite was taken from the optimized geometrical model of Zheng et al. (2017) [25] with $a=5.29 \AA, b=9.12 \AA, c=20.26 \AA$, and $\beta=95.83^{\circ}$. The mean distances and angles in the model match the experimental data within differences less than $3 \%$. In this study, the muscovite (001) surface was modeled using one TOT slab comprised of two tetrahedron layers (T) and one octahedron layer (O). Moreover, a vacuum boundary of $20 \AA$ was performed to interdict any interactions between slabs. A $2 \times 1 \times 1$ supercell containing 80 atoms was employed to calculate the surface reactions. In the surface model, the five upper atom layers were permitted to fully relax, while the two lower atom layers were fixed. A dipole correction along the $z$-direction was applied in all slab calculations. Full calculations were performed in which all structural parameters were relaxed without the constraint of the space group symmetry, namely, the space group was P1. All the simulations are intended to investigate the disruptive behavior of $\mathrm{H}$ after releasing $\mathrm{K}$. The $\mathrm{H}$ ions, due to their small atomic number and radius, can form strong interaction forces with the muscovite, so the van der Waals (dispersive) forces were not considered in the calculation. The geometry optimization was convergent when the total energy change and the forces on all unconstrained atoms were less than $10^{-5} \mathrm{eV}$ and $0.05 \mathrm{eV} / \AA$, respectively.

\subsection{Reaction Rate Model}

In this study, the climbing-image nudge elastic band (CI-NEB) method [26,27] was employed for the transition state (TS) search (saddle point of first order). Meanwhile, the harmonic vibrational frequency calculations were carried out to ensure that the TS structure has only one imaginary frequency, and the activation energy was corrected with zero-point energy. The reaction rates of chemical processes can be estimated by Eyring equation [28], an Arrhenius-like expression in the transition state theory (TST):

$$
k=\frac{k_{B} T}{h} e^{-\frac{\Delta E_{a}}{k_{B} T}}
$$

where $k$ is the rate constant of chemical processes, $k_{B}$ is the Boltzmann constant, $T$ is the absolute temperature, $h$ is the Planck's constant, $\Delta E_{a}$ is the activation energy for the reaction.

\section{Results and Discussion}

\subsection{Element Dissolution of Muscovite}

In order to determine the general process of muscovite disintegration, the dissolution rate and interaction of each element $(\mathrm{K}, \mathrm{Al}, \mathrm{Si})$ need to be clarified. The sample was treated for different leaching times and the related data of each element's dissolution is displayed in Figure 2.

The leaching efficiency of each element at various leaching times is shown in Figure 2a. It finds that $\mathrm{K}$ and $\mathrm{Al}$ release from the solid and enter solution rapidly. Oppositely, the leaching efficiency of Si nearly remains invariable and less than $1 \%$, indicating that $\mathrm{Si}$ is difficult to dissolve from the muscovite lattice and stays in the residue during the acid leaching processing. Accordingly, the dissolution of muscovite is incongruent. The correlation slope and $\gamma$ of $\mathrm{K} / \mathrm{Al}$ are both close to zero in Figure $2 \mathrm{~b}$; this approximately congruent dissolution rate between $\mathrm{K}$ and $\mathrm{Al}$ presents their linear correlations. The dissolution of $\mathrm{Al}$ implies the disintegration of octahedral sheets of muscovite where the $\mathrm{V}$ is located. Thus, the release of $\mathrm{K}$ plays a decisive role for muscovite destruction and $\mathrm{V}$ extraction. It can be inferred that weakly electrostatic $\mathrm{K}$ is firstly substituted by $\mathrm{H}$ ions. Then, the $\mathrm{H}$ ions break the stable tetrahedral sheets and expose the octahedron layers to the acid environment. Finally, Al contained in 
octahedrons can be released, reaching the complete destruction of muscovite. The reaction mechanism of $\mathrm{H}$ ions on the tetrahedral sheets needs to be further investigated.

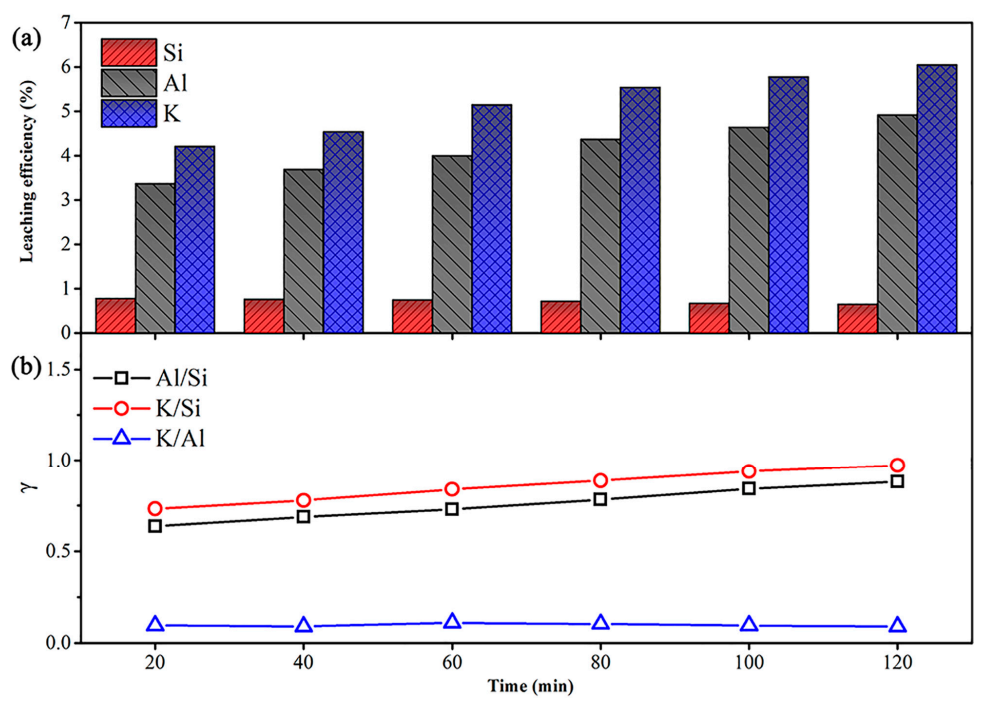

Figure 2. (a) The leaching efficiency of $\mathrm{K}, \mathrm{Al}$, and $\mathrm{Si}$; (b) the correlation of the elements' dissolution.

\subsection{Formation of the 001 Surface Hydroxyl}

The characterization of muscovite structure after releasing $\mathrm{K}$ by $\mathrm{H}$ was studied using quantum chemical simulation methods. The muscovite model in this study was calculated considering the quarter substitution of Si by Al [25]. We optimized the structure with half and all K substituted by $\mathrm{H}$ to clarify structural changes after $\mathrm{K}$ release. Interestingly, all of the $\mathrm{H}$ ions move to the border of the hexagonal cavities and stop above the unsaturated structured $\mathrm{O}\left(\mathrm{O}_{\text {un }}\right)$ atoms of the Al-O tetrahedrons from the centre of the interlayer space (Figure 3). This reveals that the $\mathrm{H}$ ions preferentially attack the unsaturated $\mathrm{O}$ of $\mathrm{Al}-\mathrm{O}$ tetrahedrons when the tetrahedral sheets are dissolving. A similar behavior is also observed for other trioctahedral phyllosilicates $[29,30]$. In order to distinguish the chemisorption or electrostatic adsorption of $\mathrm{H}$ ions on the surface of tetrahedral sheets, it is necessary to investigate the interaction between $\mathrm{H}$ and $\mathrm{O}_{u}$ and particularly the influence on the neighboring $\mathrm{Si}$ and $\mathrm{Al}$.

(a)

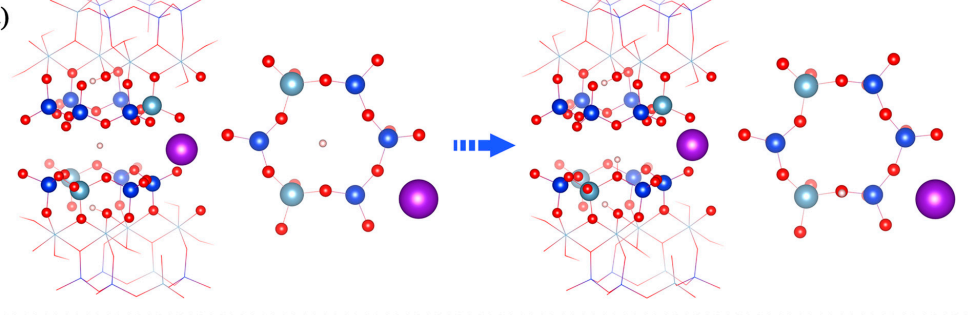

(b)

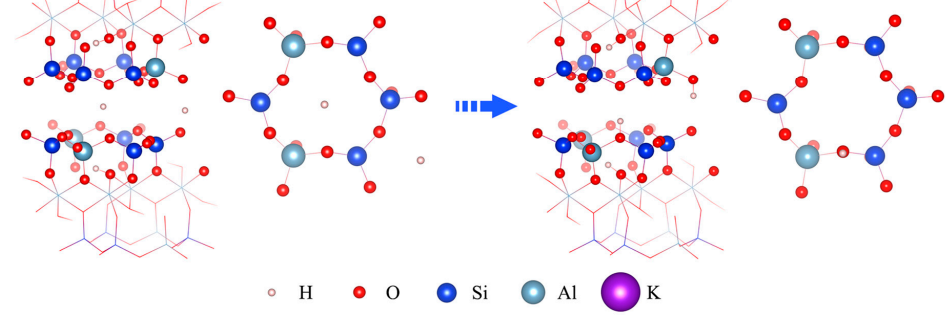

Figure 3. $\mathrm{H}$ atom migration behavior in (a) $50 \% \mathrm{~K}$ substituted by $\mathrm{H}$; (b) $100 \% \mathrm{~K}$ substituted by $\mathrm{H}$. 
For intensive study of the characteristics of $\mathrm{H}-\mathrm{O}_{\mathrm{un}}$ and $\mathrm{Si}-\mathrm{O}_{\mathrm{un}}(\mathrm{H})-\mathrm{Al}$ bonding, we estimated the electron distribution using electron localization function (ELF) map (top of Figure 4). The color transition represents the localized level of electrons; red means highly localized electrons and blue is the opposite. It can be clearly seen that the highly localized electrons between $\mathrm{H}$ and $\mathrm{O}_{\text {un }}$ are even more intensive than between the $\mathrm{Si}-\mathrm{O}$ and $\mathrm{Al}-\mathrm{O}$ bonds. In the partial densities of states (PDOS) of $\mathrm{O}_{\text {un }}$ and $\mathrm{H}$ atoms, the valence bands of the $\mathrm{O} 2 p$ states can be resolved into three states toward different orientation, $p x, p y, p z$ (bottom of Figure 4). In the substitution of $\mathrm{H}$ to $\mathrm{K}$, the $\mathrm{H} 1$ s states appear at $-8.8 \mathrm{eV}$ overlapped with the $2 p z$ states of $\mathrm{O}_{\mathrm{un}}$. It is worth pointing out that the $\mathrm{H}-\mathrm{O}_{\text {un }}$ bond presents an observable covalent component along the $c$-axis. Therefore, it can be responsibly considered that $\mathrm{H}$ chemically adsorbs on the surface of the tetrahedral sheet and forms a strong surface hydroxyl. Furthermore, the formation of the 001 surface hydroxyl stretches the near $\mathrm{Al}-\mathrm{O}$ and $\mathrm{Si}-\mathrm{O}$ bond from $1.77 \AA$ and $1.61 \AA$ to $1.90 \AA$ and $1.70 \AA$, respectively. Meanwhile, the angle of Al-O-Si declined to $1.34^{\circ}$. Namely, unsaturated $\mathrm{O}$ atoms are pulled out to the interlayer space. The longer $\mathrm{Si}-\mathrm{O}$ and Al-O distance of the latter structure shows the weaker interaction and contribution to its instability. It provides the possibility for the removal of the 001 surface hydroxyl to break the oxygen framework of tetrahedral sheets.

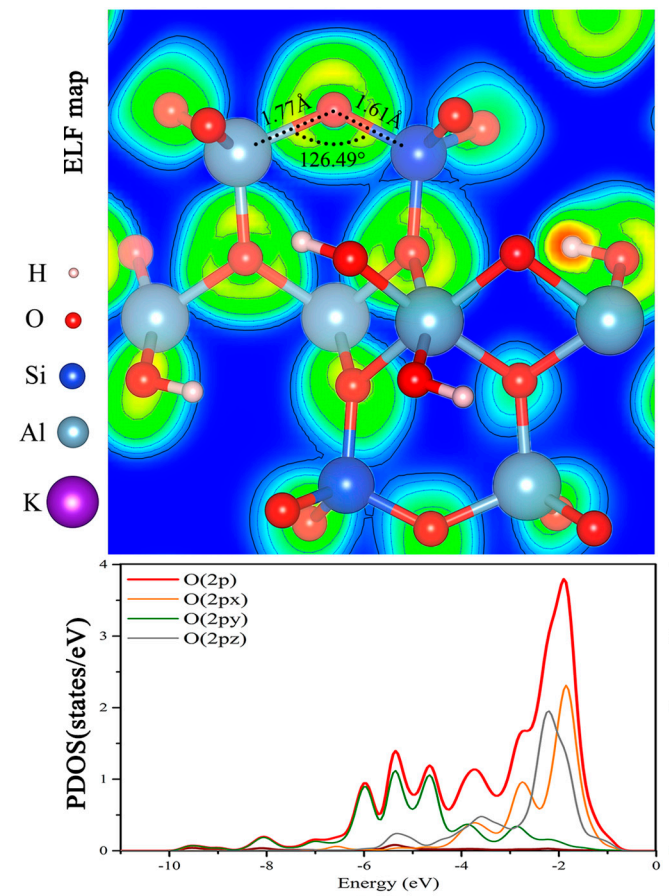

(a)
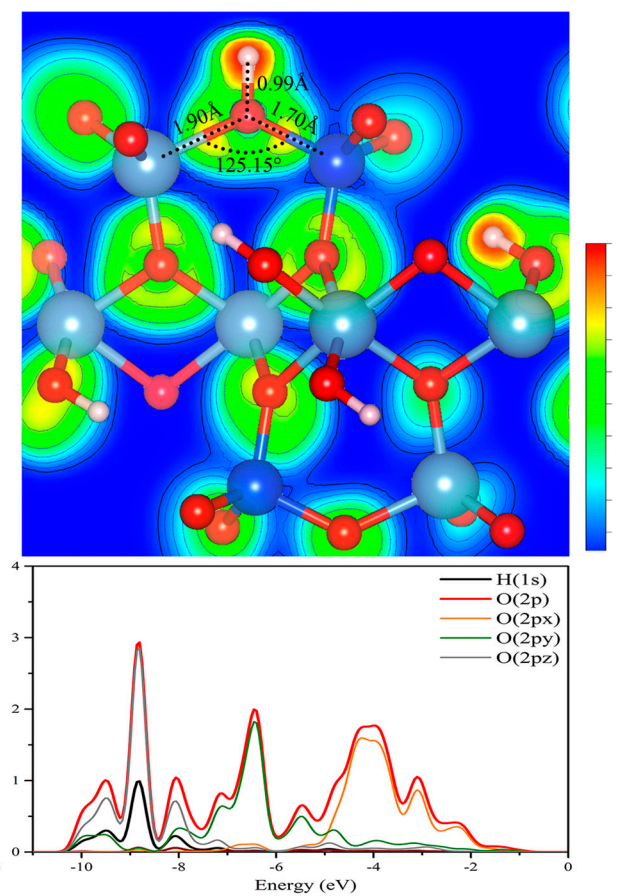

(b)

Figure 4. The electron localization function map of the (100) plane and partial densities of states (PDOS) for the $\mathrm{O}_{\mathrm{un}}$ and $\mathrm{H}$ atoms of muscovite: (a) without $\mathrm{H}$ substitution; (b) $\mathrm{K}$ substituted by $\mathrm{H}$.

\subsection{Fracture of Oxygen Framework by Dehydroxylation}

\subsubsection{Reaction Mechanisms of Dehydroxylation}

The dehydroxylation reaction constantly happens during the leaching process. We assumed that the hydrogen atom is detached from another closer surface $\mathrm{OH}$ group on the surface of a tetrahedral sheet. Additional $\mathrm{OH} \cdots \mathrm{H}$ nonbonding distances are too long to be discussed here. All the preferential distributions of two interlayer $\mathrm{OH}$ groups are compiled in Figure 5. The related energies of these six configurations were calculated. After comparison, the $\mathrm{IS}_{24}$ with the lowest related energy would be treated as the initial state of dehydroxylation. 


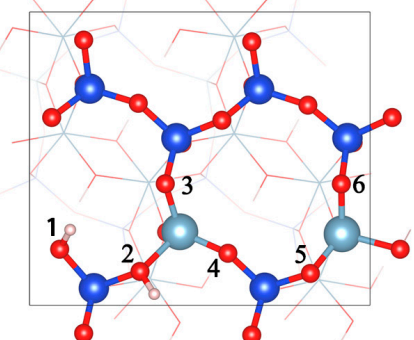

$\mathrm{IS}_{12} \quad 0.28 \mathrm{eV}$

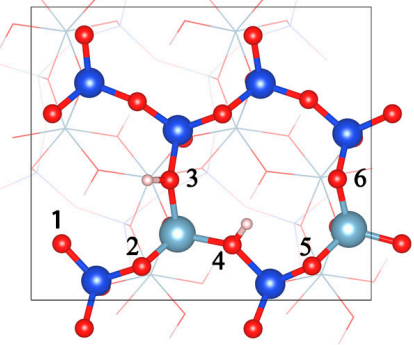

$\mathrm{IS}_{34} \quad 0.19 \mathrm{eV}$

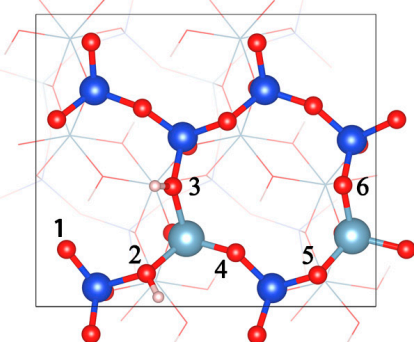

$\mathrm{IS}_{23} \quad 0.11 \mathrm{eV}$

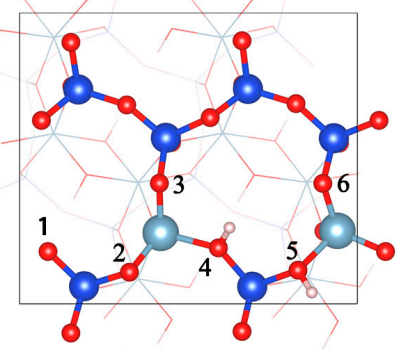

$\mathrm{IS}_{45} \quad 0.28 \mathrm{eV}$

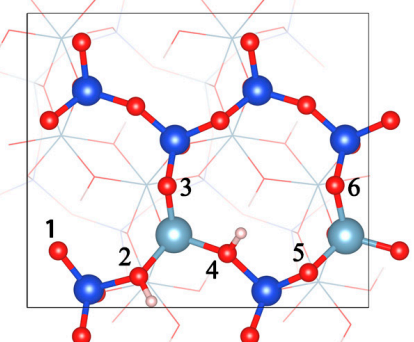

$\mathrm{IS}_{24} \quad 0.00 \mathrm{eV}$

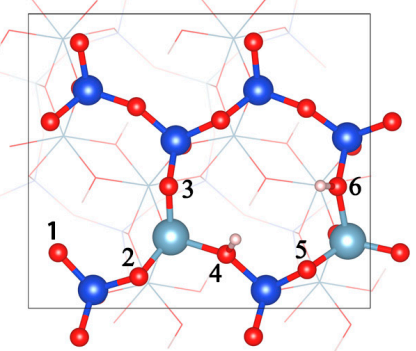

IS $_{46} \quad 0.03 \mathrm{eV}$

Figure 5. The likely distribution of two interlayer $\mathrm{OH}$ groups on the surface of muscovite and the related energy (the surface atoms are displayed with ball-stick models and the inside atoms are displayed with wireframe models).

Two steps of the dehydroxylation have been suggested: (a) the first in which just one structural water is formed on the tetrahedral sheets and (b) the second step in which the structural water is removed completely to the air [31,32]. In the diagrams, $\mathrm{H}_{2} \mathrm{O}^{*}$ denotes the free water molecule in a separate unit cell. According the structural features of $\mathrm{IS}_{24}$, two likely reaction mechanisms have been investigated: (1) the straight-path $\left(\mathrm{H}_{\mathrm{L}} \rightarrow \mathrm{O}_{\mathrm{R}} \mathrm{H}_{\mathrm{R}}\right.$, the red line in Figure 6): the left-side hydrogen atom $\left(\mathrm{H}_{\mathrm{L}}\right)$ of the surface hydroxyl $\left(\mathrm{O}_{\mathrm{L}} \mathrm{H}_{\mathrm{L}}\right)$ directly jumps to the right-side surface hydroxyl $\left(\mathrm{O}_{R} \mathrm{H}_{R}\right)$ to form the final state $\mathrm{FS}_{\text {st. }}$ (2) the reverse-path $\left(\mathrm{H}_{\mathrm{R}} \rightarrow \mathrm{O}_{\mathrm{L}} \mathrm{H}_{\mathrm{L}}\right.$, the blue line in Figure 6): the right-side hydrogen atom $\left(\mathrm{H}_{R}\right)$ of surface hydroxyl $\left(\mathrm{O}_{R} \mathrm{H}_{R}\right)$ shifts to the left-side surface hydroxyl $\left(\mathrm{O}_{L} \mathrm{H}_{L}\right)$ after two-surface hydroxyl reversing, and forms the final state, $\mathrm{FS}_{\text {re }}$.

In the straight-path mechanism, the structural water molecule is formed without a transition state (TS). The position of the structural water in $\mathrm{FS}_{\mathrm{st}}$ keeps the plane of three atoms perpendicular to the (001) plane of muscovite. This pathway is a continuous endothermic process. In the reverse-path mechanism, the $\mathrm{H}_{\mathrm{R}}$ atom extends towards the $\mathrm{O}_{\mathrm{L}} \mathrm{H}_{\mathrm{L}}$ group after both $\mathrm{OH}$ groups turn back and the $\mathrm{O}_{\mathrm{L}} \mathrm{H}_{\mathrm{L}}$ stays away from the $\mathrm{Si}$ atom to form the TS. This part of the reaction absorbs heat. Then, the $\mathrm{H}_{\mathrm{R}}$ atom completely detaches from the $\mathrm{O}_{\mathrm{R}} \mathrm{H}_{\mathrm{R}}$ group, and a structural water is finally formed after the reorientation of the hydroxyl bonds, in which the plane of structural water is almost parallel to the (001) plane of muscovite. This part of the reaction releases heat. The process of TS searching for two mechanisms are displayed in the Figures S1 and S2, respectively. The vibrational frequencies of searched TS structure are displayed in Table S1.

During the second step of the dehydroxylation reaction, the structural water is completely removed from the surface of muscovite as a free state. Remarkably, the breakage of Si-O bonds makes the old tetrahedron disintegrate and a new tetrahedron is rebuilt in both pathways, in which the central Si atom captures a hydroxyl group from the inside octahedral sheet. The shifting of these hydroxyl groups reduces the stability of the octahedrons and benefits the release of $\mathrm{Al} / \mathrm{V}$ from the octahedrons. Meanwhile, the removal of the first structural water exposes the cations ( $\mathrm{Si} / \mathrm{Al}$ ) of the tetrahedrons and provides more active sites for the attack of anions, like $\mathrm{SO}_{4}{ }^{2-}$ and $\mathrm{F}^{-}$, in the acid solution. During the continuous removal of structural $\mathrm{O}$ and $\mathrm{Si} / \mathrm{Al}$ from the tetrahedral sheets, the 
original stable framework of tetrahedral sheets gradually breaks. This process finally increases the bare area of octahedrons to the acid environment and facilitates the $\mathrm{Al}$ and $\mathrm{V}$ atoms' release. It can be inferred that the formation and removal of the 001 surface hydroxyl are the crucial steps for the destruction of muscovite's structure in the acid leaching of vanadium-bearing shale.

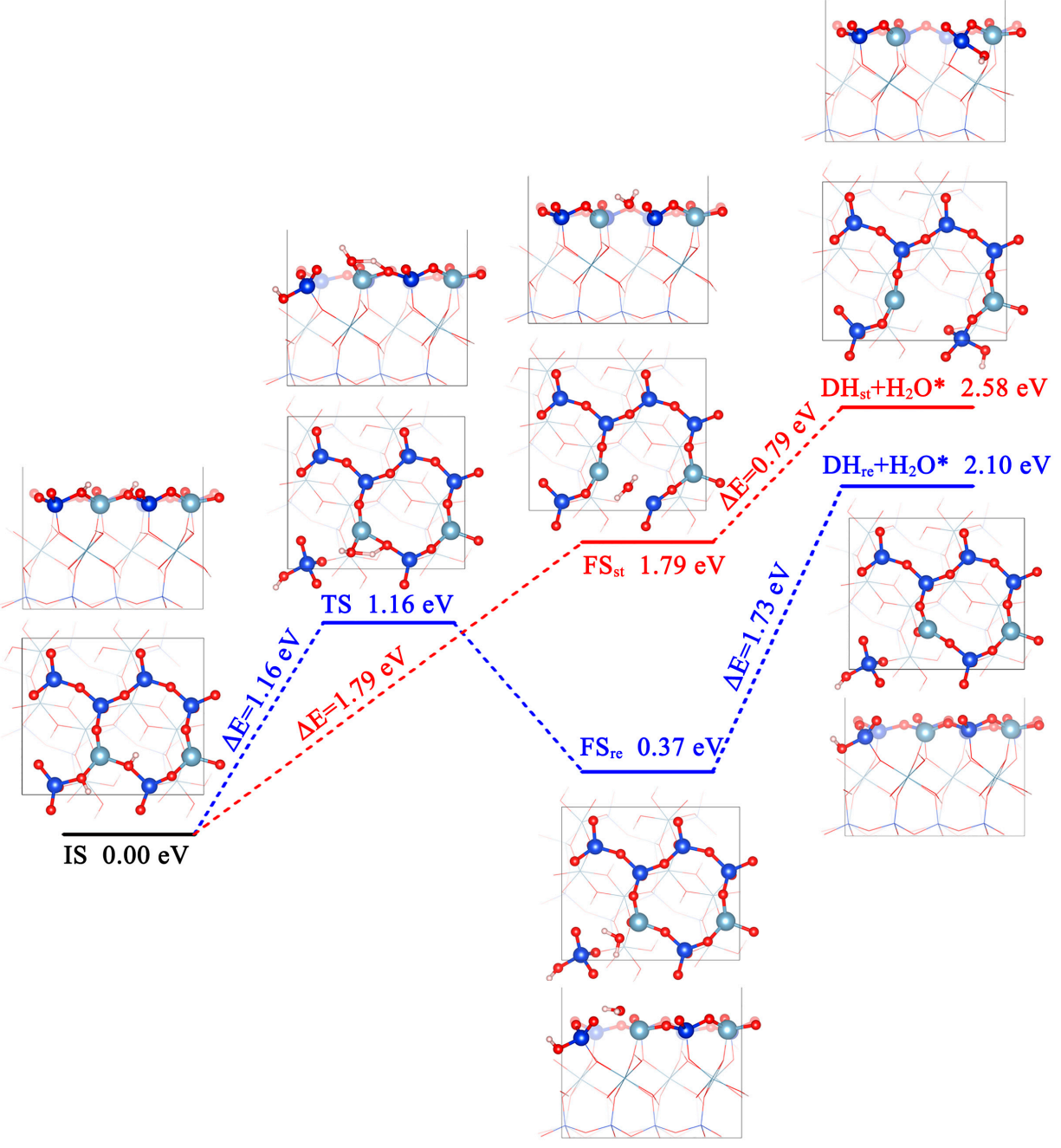

Figure 6. Potential energy diagram and geometries for the process of formation and release of structural water (the surface atoms are displayed with ball-stick models and the inside atoms are displayed with wireframe models).

\subsubsection{Reaction Rates of Dehydroxylation}

In the straight-path mechanism, the formation and release of structural water are constantly endoergic. The activation energy of structural water formation is $1.79 \mathrm{eV}$, which is larger than the activation energy of structural water desorption $(0.79 \mathrm{eV})$. In the reverse-path mechanism, the formation of structural water is initially endoergic, then exoergic, while overall it is endoergic. The release of structural water is also endoergic. The activation energy of structural water desorption $(1.73 \mathrm{eV})$ is larger than the activation energy of structural water formation $(1.16 \mathrm{eV})$. According to the Eyring equation, the rate constant of a chemical process is affected by the activation energy and temperature. The rate constant of each stage of the two pathways changing with temperature is shown in Figure 7. It suggests that the formation of structural water is the rate determining step in the straight-path mechanism, while the rate determining step becomes the removal of structural water in the reverse-path mechanism. 


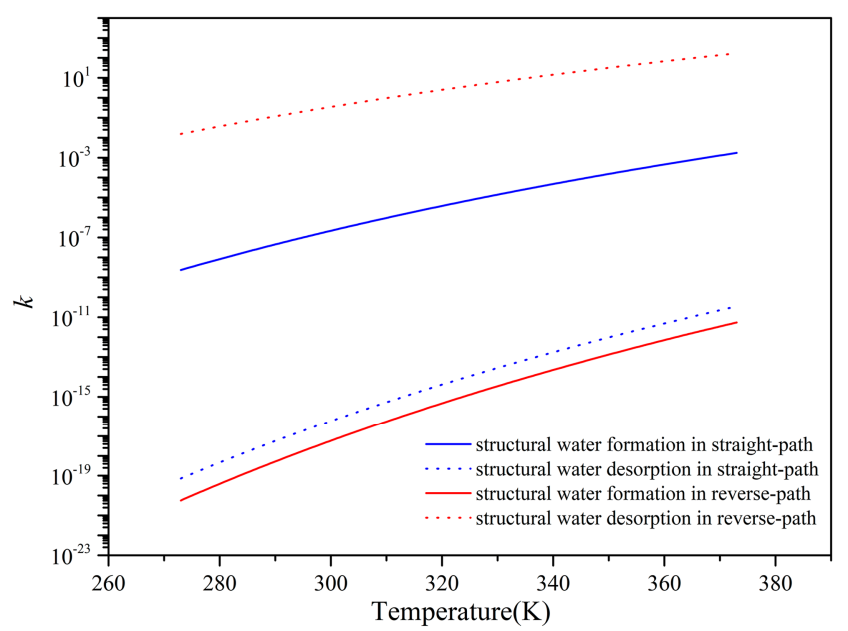

Figure 7. The rate constant of each stage of the two pathways at different temperatures.

Comparing the rate constants of the two pathways in Figure 7, the straight-path is more likely to form structural water than the reverse path. However, the release of structural water from the straight path is more difficult than from the reverse path. The rearrangement of structural water in the reverse-path mechanism produce a more stable final state ( $\mathrm{FS}_{\mathrm{re}}$ in Figure 6), in which the structural water forms hydrogen bonds with the structural oxygen atoms and the closed $\mathrm{Al} \cdots \mathrm{O}_{\mathrm{L}}$ distance retains the strong electrostatic force. Instead, the complete desorption of this water needs to absorb much more heat. While the structure after dehydration in the reverse-path mechanism retains a lower free energy than the straight-path mechanism. Thus, the reverse-path mechanism is kinetically more feasible than the straight-path mechanism due to the lower activation energy of the structural water formation as well as the more stable hydration and dehydration structure. In total, the high leaching temperature is beneficial to the dehydroxylation of the oxygen framework and promotes the destruction of muscovite and vanadium release.

\section{Conclusions}

In this work, we have studied the process of muscovite structure destruction during vanadium extraction from black shale by a combination of experimental analysis and DFT calculations. The leaching experiment showed that the $\mathrm{K}$ is initially released and the dissolution of $\mathrm{Al}$ is correlated to $\mathrm{K}$ during the disintegration of muscovite. The simulation results further found that $\mathrm{H}$ ions preferentially attack the unsaturated structured $\mathrm{O}$ atoms of the Al-O tetrahedron to form strong 001 surface hydroxyls which reduces the stability of the adjacent $\mathrm{Si}-\mathrm{O}$ and $\mathrm{Al}-\mathrm{O}$ bonds. Two likely pathways of the dehydroxylation reaction were investigated, in which the process of structural water formation and removal are overall endoergic, while the reverse-path mechanism is kinetically more feasible than the straight-path mechanism due to its lower activation energy in the formation of structural water and more stable hydration and dehydration structure. Then, the continuous formation and removal of 001 surface hydroxyls will aggravate the damage of the oxygen framework of tetrahedral sheets and further expose the octahedrons, finally promoting $\mathrm{Al} / \mathrm{V}$ release into solution. This study visually expounded the removal process of structural oxygen from muscovite by $\mathrm{H}$ ions during the acid leaching process, and provided a new method and a theoretical basis for the further study of $\mathrm{Al}$ and $\mathrm{V}$ release from muscovite in black shale at the atomic scale.

Supplementary Materials: The following are available online at http:/ / www.mdpi.com/2075-163X/8/5/208/s1, Figure S1: The reaction process of reverse-path mechanism, Figure S2: The reaction process of straight-path mechanism, Table S1: The vibrational frequencies of searched structure. 
Author Contributions: Q.Z. and Y.Z. conceived and designed the experiments; Q.Z. and N.X. performed the calculations and analyzed the data; Y.Z., T.L. and J.H. contributed servers/softwares/analysis tools; and Q.Z. wrote this paper.

Acknowledgments: This work was supported by the National Natural Science Foundation of China (No. 51474162, No. 51404174) and the National Key Science-Technology Support Programs of China (No. 2015BAB18B01).

Conflicts of Interest: The authors declare no conflict of interest.

\section{References}

1. Koust, S.; Reinecke, B.N.; Adamsen, K.C.; Beinik, I.; Handrup, K.; Li, Z.S.; Moses, P.G.; Schnadt, J.; Lauritsen, J.V.; Wendt, S. Coverage-dependent oxidation and reduction of vanadium supported on anatase TiO2(101). J. Catal. 2018, 360, 118-126. [CrossRef]

2. Motola, M.; Satrapinskyy, L.; Caplovicova, M.; Roch, T.; Gregor, M.; Grancic, B.; Gregus, J.; Caplovic, L.; Plesch, G. Enhanced photocatalytic activity of hydrogenated and vanadium doped $\mathrm{TiO}_{2}$ nanotube arrays grown by anodization of sputtered Ti layers. Appl. Surf. Sci. 2018, 434, 1257-1265. [CrossRef]

3. Crans, D.C.; Yang, L.N.; Haase, A.; Yang, X.G. Health benefits of vanadium and its potential as an anticancer agent. Met. Ions Life Sci. 2018, 18, 251-279.

4. Marques, M.P.M.; Gianolio, D.; Ramos, S.; Batista de Carvalho, L.A.E.; Aureliano, M. An EXAFS approach to the study of polyoxometalate-protein interactions: The case of decavanadate-actin. Inorg. Chem. 2017, 56, 10893-10903. [CrossRef] [PubMed]

5. Zhang, Y.M.; Bao, S.X.; Liu, T.; Chen, T.J.; Huang, J. The technology of extracting vanadium from stone coal in China: History, current status and future prospects. Hydrometallurgy 2011, 109, 116-124. [CrossRef]

6. Zhang, Y.M.; Hu, Y.J.; Bao, S.X. Vanadium emission during roasting of vanadium-bearing stone coal in chlorine. Miner. Eng. 2012, 30, 95-98. [CrossRef]

7. Ye, P.H.; Wang, X.W.; Wang, M.Y.; Fan, Y.Y.; Xiang, X.Y. Recovery of vanadium from stone coal acid leaching solution by coprecipitation, alkaline roasting and water leaching. Hydrometallurgy 2012, 117, 108-115. [CrossRef]

8. Cai, Z.L.; Zhang, Y.M. Phase transformations of vanadium recovery from refractory stone coal by novel $\mathrm{NaOH}$ molten roasting and water leaching technology. RSC Adv. 2017, 7, 36917-36922. [CrossRef]

9. Hu, K.L.; Liu, X.H.; Li, Q.G. Extracting vanadium from stone coal by a cyclic alkaline leaching method. Metall. Mater. Trans. B 2017, 48, 1342-1347. [CrossRef]

10. Wang, F.; Zhang, Y.M.; Liu, T.; Huang, J.; Zhao, J.; Zhang, G.B.; Liu, J. A mechanism of calcium fluoride-enhanced vanadium leaching from stone coal. Int. J. Miner. Process. 2015, 145, 87-93. [CrossRef]

11. Hu, P.C.; Zhang, Y.M.; Huang, J.; Liu, T.; Yuan, Y.Z.; Xue, N.N. Eco-friendly leaching and separation of vanadium over iron impurity from vanadium-bearing shale using oxalic acid as a leachant. ACS Sustain. Chem. Eng. 2018, 6, 1900-1908. [CrossRef]

12. Yuan, Y.Z.; Zhang, Y.M.; Liu, T.; Chen, T.J. Comparison of the mechanisms of microwave roasting and conventional roasting and of their effects on vanadium extraction from stone coal. Int. J. Min. Met. Mater. 2015, 22, 476-482. [CrossRef]

13. Xue, N.N.; Zhang, Y.M.; Liu, T.; Huang, J.; Liu, H.; Chen, F. Mechanism of vanadium extraction from stone coal via hydrating and hardening of anhydrous calcium sulfate. Hydrometallurgy 2016, 166, 48-56. [CrossRef]

14. Crundwell, F.K. The mechanism of dissolution of minerals in acidic and alkaline solutions: Part II application to a new theory to silicates, aluminosilicates and quartz. Hydrometallurgy 2014, 149, 265-275. [CrossRef]

15. Crundwell, F.K. The mechanism of dissolution of minerals in acidic and alkaline solutions: Part VI a molecular viewpoint. Hydrometallurgy 2016, 161, 34-44. [CrossRef]

16. Hernández-Haro, N.; Ortega-Castro, J.; Valle, C.P.D.; Muñoz-Santiburcio, D.; Sainz-Díaz, C.I.; Hernández-Laguna, A. Computational study of the elastic behavior of the 2M1 muscovite-paragonite series. Am. Miner. 2013, 98, 651-664. [CrossRef]

17. Ortega-Castro, J.; Hernández-Haro, N.; Hernández-Laguna, A.; Sainz-Díaz, C.I. DFT calculation of crystallographic properties of dioctahedral 2:1 phyllosilicates. Clay Miner. 2008, 43, 351-361. [CrossRef]

18. Ulian, G.; Valdrè, G. Density functional investigation of the thermo-physical and thermo-chemical properties of 2M1 muscovite. Am. Miner. 2015, 100, 935-944. [CrossRef] 
19. Kresse, G.; Hafner, J. Ab initio molecular dynamics for open-shell transition metals. Phys. Rev. B 1993, 48, 13115-13118. [CrossRef]

20. Kresse, G.; Furthmüller, J. Efficiency of ab initio total energy calculations for metals and semiconductors using a plane-wave basis set. Comput. Mater. Sci. 1996, 6, 15-50. [CrossRef]

21. Perdew, J.P.; Burke, K.; Wang, Y. Generalized gradient approximation for the exchange-correlation hole of a many-electron system. Phys. Rev. B 1996, 54, 16533-16539. [CrossRef]

22. Perdew, J.P.; Chevary, J.A.; Vosko, S.H.; Jackson, K.A.; Pederson, M.R.; Singh, D.J.; Fiolhais, C. Atoms, molecules, solids, and surfaces: Applications of the generalized gradient approximation for exchange and correlation. Phys. Rev. B 1992, 46, 6671-6687. [CrossRef]

23. Blöchl, P.E. Projector augmented-wave method. Phys. Rev. B 1994, 50, 17953-17979. [CrossRef]

24. Kresse, G.; Joubert, D. From ultrasoft pseudopotentials to the projector augmented-wave method. Phys. Rev. B 1999, 59, 1758-1775. [CrossRef]

25. Zheng, Q.S.; Zhang, Y.M.; Liu, T.; Huang, J.; Xue, N.N.; Shi, Q.H. Optimal location of vanadium in muscovite and its geometrical and electronic properties by DFT calculation. Minerals 2017, 7, 32. [CrossRef]

26. Henkelman, G.; Jónsson, H. Improved tangent estimate in the nudged elastic band method for finding minimum energy paths and saddle points. J. Chem. Phys. 2000, 113, 9978-9985. [CrossRef]

27. Henkelman, G.; Uberuaga, B.P.; Jónsson, H. A climbing image nudged elastic band method for finding saddle points and minimum energy paths. J. Chem. Phys. 2000, 113, 9901-9904. [CrossRef]

28. Sholl, D.S.; Steckel, J.A. Density Functional Theory—A Practical Introduction; John Wiley \& Sons: Hoboken, NJ, USA, 2009; pp. 131-158.

29. Moro, D.; Ulian, G.; Valdrè, G. Nanoscale cross-correlated AFM, Kelvin probe, elastic modulus and quantum mechanics investigation of clay mineral surfaces: The case of chlorite. Appl. Clay Sci. 2016, 131, 175-181. [CrossRef]

30. Valdrè, G.; ToSoni, S.; Moro, D. Zeolitic-type Brønsted-Lowry sites distribution imaged on clinochlore. Am. Miner. 2011, 96, 1461-1466. [CrossRef]

31. Molina-Montes, E.; Donadio, D.; Hernández-Laguna, A.; Sainz-Díaz, C.I.; Parrinello, M. DFT Research on the Dehydroxylation Reaction of Pyrophyllite 1. First-Principle Molecular Dynamics Simulations. J. Phys. Chem. B 2008, 112, 7051-7060. [CrossRef] [PubMed]

32. Molina-Montes, E.; Donadio, D.; Hernández-Laguna, A.; Sainz-Díaz, C.I.; Parrinello, M. DFT Research on the Dehydroxylation Reaction of Pyrophyllite 2. Characterization of Reactants, Intermediates, and Transition States along the Reaction Path. J. Phys. Chem. A 2008, 112, 6373-6383. [CrossRef] [PubMed] 